\title{
DÜBLIN
}

Technological University Dublin

ARROW@TU Dublin

2010-01-01

\section{The Antioxidant Properties of Whey Permeate Treated Fresh-Cut Tomatoes}

\author{
Lubna Ahmed \\ Technological University Dublin, lubna.ahmed@tudublin.ie \\ Ana Belen Martin-Diana \\ Technological University Dublin, anabelen.martindiana@tudublin.ie \\ Daniel Rico \\ Technological University Dublin
}

See next page for additional authors

Follow this and additional works at: https://arrow.tudublin.ie/schfsehart

Part of the Other Chemistry Commons

\section{Recommended Citation}

Ahmed, L. et al:The Antioxidant Properties of Whey Permeate Treated Fresh-Cut Tomatoes. Food Chemistry, 2010 doi:10.1016/j.foodchem.2010.07.106

This Article is brought to you for free and open access by the School of Food Science and Environmental Health at ARROW@TU Dublin. It has been accepted for inclusion in Articles by an authorized administrator of ARROW@TU

Dublin. For more information, please contact

arrow.admin@tudublin.ie, aisling.coyne@tudublin.ie, gerard.connolly@tudublin.ie.

Funder: DIT Strand I Research Project (2006-2010)

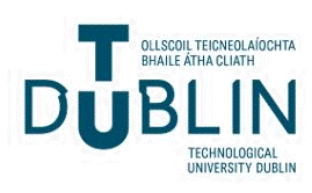




\section{Authors}

Lubna Ahmed, Ana Belen Martin-Diana, Daniel Rico, and Catherine Barry-Ryan

This article is available at ARROW@TU Dublin: https://arrow.tudublin.ie/schfsehart/12 


\section{Full Title}

The antioxidant properties of whey permeate treated fresh-cut tomatoes

4

5

6

Names(s) Authors(s)

8

L. Ahmed*, A. B. Martin-Diana, D. Rico and C. Barry-Ryan

9

10

11

20 *Corresponding Author: Lubna Ahmed, School of Food Science and Environmental

21 Health, Dublin Institute of Technology (DIT), Cathal Brugha Street, Dublin 1, Ireland.

22 Phone: 35314024442, Fax: +35314024495, e-mail: $\underline{\text { lahmed@ dit.ie }}$ 


\section{Abstract:}

24 The aim of this research was to analyse the effects of three types of cheese whey permeate

25 treatment on the antioxidant properties of fresh-cut tomatoes. Tomatoes were treated with

26 whey permeate concentrate (PC), delactosed permeate (DP) and delactosed concentrate

27 (DC), stored at $4^{\circ} \mathrm{C}$ for 10 days and compared to the samples treated with industrial

28 standard, chlorine (120 ppm). Samples were analysed for ascorbic acid, lycopene, total

29 phenols, mineral and trace elements and antioxidant activity (DPPH and FRAP). The

30 samples treated with DP retained significantly $(\mathrm{p}<0.05)$ higher antioxidant activity (FRAP)

31 and total phenols (TP) when compared with those treated with PC and DC respectively. DP

32 showed significantly $(\mathrm{p}<0.05)$ higher results than chlorine for DPPH, FRAP and TP. In

33 DPPH assay, all whey permeate-treated samples showed similar antioxidant activity. No

34 significant differences in levels were found among whey permeates and chlorine treatments

35 for naturally present antioxidants such as ascorbic acid and lycopene. The statistical

36 analysis showed a positive significant $\left(\mathrm{R}^{2}=0.9173, \mathrm{p}<0.05\right)$ correlation between $\mathrm{TP}$ and the

37 antioxidant activity. A good correlation was observed between DPPH and FRAP assay

$38\left(\mathrm{R}^{2}=0.8005, \mathrm{p}<0.05\right)$. Among the three whey permeates, delactosed permeate showed the

39 best results in maintaining the antioxidant properties of tomato. These results suggest that

40 whey permeate could be used to enhance the antioxidant activity of the fresh-cut tomato

41 while retaining the antioxidant components during storage.

42 Key words: Whey permeate, Ascorbic acid, Lycopene, Antioxidant activity, Total phenols, 43 Minerals. 


\section{Introduction}

45 The consumption of a diet rich in fresh fruits and vegetables has been associated with a

46 number of health benefits including the prevention of chronic diseases (WHO, 2003). This

47 beneficial effect is believed to be due, at least partially, to the action of antioxidant

48 compounds, which reduce oxidative damage in the body (Lana \& Tijskens, 2006). While

49 the prescription of supplements containing antioxidants has resulted in contradictory results

50 upon human health, the results from epidemiological studies comparing populations with

51 different diets show a clear trend in reduction of chronic diseases when there is an increase

52 in the consumption of fruits and vegetables (Meléndez-Martínez, Fraser, \& Bramley, 2010).

53 Campaigns (i.e. 5 a day) to increase the consumption of these products have been launched

54 in many countries.

55 Tomato is a versatile vegetable that is consumed fresh as well as in the form of processed

56 products. Tomatoes and tomato products are rich in health-related food components as they

57 are good sources of carotenoids (in particular, lycopene), ascorbic acid (vitamin C), vitamin

58 E, folate and flavonoids. In addition, tomato contains essential amino acids, and particularly

59 high amounts of minerals ( $\mathrm{Fe}, \mathrm{Mn}, \mathrm{Zn}$, and $\mathrm{Cu}$ ) and monounsaturated fatty acids

60 (especially, oleic acid). Regular consumption of tomatoes has been correlated with a

61 reduced risk of various types of cancer and heart diseases (Lavelli, Peri \& Rizzolo, 2000).

62 These positive effects are believed to be attributable to the antioxidants, particularly

63 carotenoids, flavonoids, lycopene and $\beta$-carotene (Odriozola-Serrano, Soliva-Fortuny \&

64 Martin-Belloso, 2008). Furthermore, recommendations to increase daily intake of fruits and

65 vegetables rich in nutrients such as carotenoids and vitamins $\mathrm{C}$ and $\mathrm{E}$ to lower the markers

66 of risk of cancer and cardiovascular diseases (CVD) have been made (Sgherri, Kadlecova,

67 Pardossi, Navari-Izzo, \& Izzo, 2008). Giovannucci (2002) reviewed a number of 
68 epidemiological studies and concluded that the intake of tomato products was consistently

69 associated with a lower risk of a variety of cancers and in particular prostate cancer. The

70 fresh-cut industry claims their products are convenient and healthy alternatives to fulfil the

71 dietary needs for fresh food and many fast food companies are diversifying their menu in

72 order to offer a range of ready-to-eat salads to their clients. However, the many changes that

73 happen in fruits and vegetables during harvesting, handling and processing can affect

74 antioxidant status. Fresh cut tissues are primarily exposed to oxidative stress, presumably

75 causing membrane damage and altering the composition and content of antioxidant

76 compounds, resulting in changes in the total antioxidant activity of the tissue. Decrease in

77 the antioxidant activity after processing was reported for fresh-cut spinach (Gil, Aguayo \&

78 Kader, 2002). Many researchers have routinely used sodium hypochlorite for surface

79 sanitation and sterilisation of fruits and vegetables. For tomato, a range of $0.105-1.05 \%$

80 sodium hypochlorite (1:50 - 1:5 dilutions of commercial bleach) is commonly used with

81 washing or dipping for 1 to $3 \mathrm{~min}$ to sterilise the surface of fruit before experimentation

82 (Artes, Conesa, Hernandez \& Gil, 1999; Martin-Diana, Rico, Frias, Mulcahy, Henehan \&

83 Barry-Ryan, 2006). Commercially, generally only 100-200 ppm chlorine is used for

84 sanitation purposes. However, the chlorine derivatives are not considered safe compounds

85 since they react with organic material to form reactive by-products such as chloramines and

86 trihalometanes, which are considered as potential carcinogenic and may provoke

87 detrimental effect in the organoleptic properties of food products (Hua \& Reckhow, 2007).

88 There is a need to investigate the efficiency of natural bio-active compounds and alternative

89 techniques.

90 Alternatives or modified methods have been proposed, however, none have yet gained

91 widespread acceptance by the industry. These include organic acids, essential oil 
92 treatments, irradiation, heat-shock, ozone treatment, etc. (Ponce, Roura, del Valle \& Fritz,

93 2002; Singh, Singh, Bhunia \& Stroshine, 2002). Each has its advantages and disadvantages,

94 where the disadvantages are dominating. The maintenance of the quality of fresh produce is

95 still a major challenge for the food industry. In recent years, there is a renewed growing

96 interest in the use of natural products for the preservation of fresh-cut produce. Research

97 and commercial applications have shown that natural components could replace traditional

98 washing agents (Gil et al., 2002; Martin-Diana et al., 2006). The developments of chlorine-

99 free fruit and vegetable products enriched with natural bio-products could contribute greatly

100 to a new and growing market, where the consumers' health-related concerns are met.

101 Natural antioxidants are of main interest nowadays. Synthetic antioxidants are widely used

102 in the food industry but consumers concerns over their safety and toxicity have forced the

103 food industry to find natural sources of antioxidant (Mukhopadhyay, 2007).

104 Whey permeate is a by-product of the production of whey protein concentrates from cheese

105 whey. The main ingredients of whey permeate are water, lactose, peptides and minerals.

106 The high chemical oxygen demand (COD) (50 kg $\mathrm{O}_{2} /$ ton permeate) of whey makes its

107 disposal a significant pollution problem. The cost-effective disposal of whey is a major

108 problem for cheese manufacturers, despite the variety of techniques available. Whey is used

109 as a fermentation feedstock for the production of lactic acid, acetic acid, propionic acid,

110 ethanol, and single cell protein, etc. (NyKänen, Lapvetelainen, Hietnen \& Kallio, 1998).

111 However, these applications still do not utilise all the whey produced and new uses for this

112 by-product are continually being sought. Whey and whey ultrafiltration permeate have been

113 proposed to be used as a natural antioxidant in foods (del Mar Contreras, Hernández-

114 Ledesma, Amigo, Martín-Álvarez, \& Recio, 2010). Their application into other products

115 would help the cheese industry to partially solve the problem of whey disposal. Whey 
116 protein is widely used as a bioactive and nutritional ingredient in health and food products

117 (Marshall, 2004). $\beta$-Lactoglobulin $(\beta$-Lg) is a small, soluble globular protein with a variety

118 of useful nutritional and functional-food characteristics that have made it an ingredient of

119 choice in the formulation of modern foods and beverages. $\beta$-Lg exhibits a growing number

120 of biological effects including anti-hypertensive, anti-cancer, hypocholesterolemic,

121 opiodergic, and anti-microbial activities (Yalcin, 2006). $\alpha$-Lactalbumin ( $\alpha$-La) is another

122 major whey protein which is one of the few proteins that remains intact upon pasteurisation,

123 and is a calcium binding protein that enhances calcium absorption. It is also a rich source of

124 the amino acids - lysine, leucine, threonine, tryptophan and cysteine (Permyakov \&

125 Berliner, 2000). Whey could be a promising natural bio-active alternative to chlorine.

126 Martin-Diana et al., 2006 successfully used whey permeate for decontamination of fresh-cut

127 lettuce and carrots during storage.

128 Therefore this study was carried out to investigate the efficacy of whey permeate for

129 maintaining and also enhancing the antioxidant components and antioxidant activity during

130 storage of fresh-cut tomatoes.

\section{2. Materials and Methods}

132 2.1. Sampling and treatment design

133 Irish vine ripened tomatoes (Lycopersicon esculentum L. Mill.) cv. Moneymaker were

134 purchased from a local supermarket (Dunnes Stores). According to the grower, the tomato

135 plants were grown commercially in a greenhouse with a $14 \mathrm{~h}$ light period from February

136 until November. The aerial environment of the greenhouse and crop irrigation and nutrition

137 were precisely controlled. The temperature of the greenhouse was $16-21^{\circ} \mathrm{C}$ which is

138 optimum for lycopene synthesis in tomato fruits. The tomatoes were then brought to the

139 food processing lab and stored at $4^{\circ} \mathrm{C}$ before processing. The experiments were carried out 
140 between March and November. Three independent trials were carried out. Each experiment

141 was conducted with 180 fresh-cut tomato packages (4 measurement days (day 1, day 3, day

1427 and day 10) $\times 5$ treatments $\times 3$ replications $\times 3$ Batches $).$

\section{2.2. Preparation of treatment solution}

144 Three different types of whey permeate (liquid) were kindly supplied by Glanbia Ltd.

145 Ingredients, Ireland. The permeate concentrate (PC) was pre-concentrated by evaporation

146 before the lactose crystallisation process. Delactosed permeate (DP) was obtained after

147 removal of lactose crystals. The delactosed permeate (DP) was then concentrated further by

148 evaporation to give delactosed concentrate (DC).

149 Five washing treatments were conducted in parallel, using the same batch of product. The

150 samples were washed with water, chlorinated water (120 ppm) and whey permeates (PC,

$151 \mathrm{DP}$ and DC) at 3\% (v/v) concentration (Martin-Diana et al., 2006). The $\mathrm{pH}$ for permeate

152 concentrate solution was 5.59, for delactosed permeate solution 5.08 and for delactosed

153 concentrate solution 4.82. Chlorinated water was prepared by diluting sodium hypochlorite

154 (13\% free chlorine, Aldrich Chemical Co., Dublin, Ireland) with distilled water to obtain a

$155 \sim 120 \mathrm{ppm}$ free chlorine solution $(\mathrm{pH}$ 8.0). For all treatments the solutions were prepared

156 using distilled water stored at room temperature.

\section{2.3. Processing and experimental set up}

158 Whole tomatoes were rinsed briefly in water prior to washing in order to avoid soil

159 contamination. Washing treatments were performed by immersion of the tomatoes in each

160 treatment solution for 1 min (with agitation). Each treatment was carried out in different

161 baskets (200 g tomatoes/L). After washing, the tomatoes were dried for $5 \mathrm{~min}$ using a salad

162 spinner. The tomatoes were then sliced $6 \mathrm{~mm}$ in thickness with a commercial slicing 
163 machine (Maxwell chase MCT-25, Baltimore Innovations, UK). Processed tomatoes were

164 then pooled, mixed and $\sim 100$ grams placed in a polypropylene tray $(180 \mathrm{~mm}$ length $\times 130$

$165 \mathrm{~mm}$ width $\times 25 \mathrm{~mm}$ depth) from Sharp Interpack Ltd., UK containing one layer of absorbent

166 paper on the bottom (Fresh-R-Pax absorbent pads, Maxwell Chase Technologies, Atlanta).

167 The principal ingredient in fresh-R-Pax absorbent pads is food grade sodium carboxymethyl

168 cellulose (CMC), a common ingredient in ice-cream, sauces, low-fat foods, etc. The trays

169 were then packaged in bags $(200 \times 320 \mathrm{~mm})$ of $35 \mu \mathrm{m}$ oriented polypropylene film (OPP)

170 with permeability at $23^{\circ} \mathrm{C}$ and $90 \% \mathrm{RH}$ of $3.3 \times 10^{-12} \mathrm{~mol} / \mathrm{s} / \mathrm{m}^{2} / \mathrm{Pa}$ for $\mathrm{O}_{2}$ and $3.1 \times 10^{-9}$

$171 \mathrm{~mol} / \mathrm{s} / \mathrm{m}^{2} / \mathrm{Pa}$ for $\mathrm{CO}_{2}$ (Amcor Flexibles Europe-Brighouse, United Kingdom). The packages

172 were then heat-sealed under atmospheric conditions and stored at $4^{\circ} \mathrm{C}$ for 10 days (Gil et

173 al., 2002; Martin-Diana et al., 2006).

\section{2.4. Nutritional markers of Fresh-cut Tomato}

175 Different nutritional markers such as ascorbic acid, lycopene, total phenol, minerals and

176 trace elements and antioxidant activity (DPPH and FRAP) were monitored throughout the

17710 days of storage of fresh-cut tomato packages stored at $4^{\circ} \mathrm{C}$.

\section{2.4.1. Ascorbic acid}

179 The ascorbic acid content in fresh-cut tomatoes was analysed by HPLC with a slight

180 modification of the method described by Lee and Castle (2001). A tomato sample (2.5 g)

181 was weighed and $25 \mathrm{ml}$ of $6 \%$ metaphosphoric acid (pH 3.0) was added to it. The sample

182 was then homogenised for $1 \mathrm{~min}$ at 24,000 rpm using an Ultra-Turrax T-25 Tissue

183 homogeniser. Then the sample was shaken with a Gyrotory Shaker G-2 (USA) for 2 hrs at

$184150 \mathrm{rpm}$ and centrifuged for $15 \mathrm{~min}$ at 3,000 $\mathrm{rpm}$ at $4^{\circ} \mathrm{C}$ ) (Sanio MSE Mistral 3000ii, UK).

185 Following centrifugation, $10 \mathrm{ml}$ of the supernatant was filtered through PTFE syringe filters 
186 (pore size $0.45 \mu \mathrm{m}$, Phenomenex, UK) and stored at $-20^{\circ} \mathrm{C}$ in foil covered plastic test tubes

187 for further analysis by HPLC.

188 The analysis of ascorbic acid content was performed with Waters 600 Satellite HPLC, with

189 a reversed phase analytical $5 \mu \mathrm{m}$ particle diameter, polymeric $\mathrm{C}_{18}$ column $(150 \times 4.6 \mathrm{~mm}, 5$

$190 \mu \mathrm{m}$ ) (Waters, Ireland) with a UV-tuneable absorbance detector (Waters 486) for

191 spectrometric peak. Ten $\mu$ of the sample was injected on a reverse phase $\mathrm{C}_{18}$ HPLC

192 column. An isocratic mobile phase of $25 \mathrm{mM}$ monobasic potassium phosphate (pH 3.0)

193 with a flow rate of $1.0 \mathrm{ml} / \mathrm{min}$ was used. The sample was detected at $230 \mathrm{~nm}$ on a Shimadzu

194 SPD-10AV, UV-visible detector. Five concentrations of ascorbic acid standard in $6 \%$

195 metaphosphoric acid in the range $10-50 \mu \mathrm{g} / \mathrm{ml}$ were injected and peak area and height were

196 determined.

197 2.4.2. Lycopene

198 Ten grams of tomato samples were weighed and transferred into a $100 \mathrm{~mL}$ beaker (wrapped

199 with aluminium foil). A 50-mL volume of hexane-acetone-ethanol solution $(2: 1: 1 \mathrm{v} / \mathrm{v} / \mathrm{v})$

200 containing 2.5\% BHT was added to solubilise the lycopene (Shi \& Le Maguer, 2000).

201 Following this the samples were homogenised with an Ultra-Turrax T-25 tissue

202 homogeniser for $1 \mathrm{~min}$ at $20,500 \mathrm{rpm}$. The samples were then shaken with a Gyrotory

203 Shaker G-2 (USA) for $2 \mathrm{hrs}$ at $150 \mathrm{rpm}$ followed by $10 \mathrm{~mL}$ of distilled water was added and

204 stirred for additional $10 \mathrm{~min}$. The polar and non-polar layers were separated, and the upper

205 hexane layer was collected and filtered through a $0.45 \mu \mathrm{m}$ PVDF membrane filter. It was

206 transferred to a new $15 \mathrm{ml}$ aluminium wrapped test tubes and kept at $-80^{\circ} \mathrm{C}$ for analysis.

207 The analysis of lycopene was performed with Waters 600 Satellite HPLC, with a reversed

208 phase analytical $5 \mu \mathrm{m}$ particle diameter, polymeric $\mathrm{C}_{18}$ column $(150 \times 4.6 \mathrm{~mm}, 5 \mu \mathrm{m})$

209 (Waters, Ireland) with a UV tuneable absorbance detector (Waters 486) for spectrometric 
210 peak. The lycopene peaks were identified at $475 \mathrm{~nm}$. An isocratic mobile phase of methyl t-

211 butyl ether/methanol/ethyl acetate (40:50:10, v/v) with a flow rate of $1 \mathrm{ml} / \mathrm{min}$ was used.

212 The column temperature and mobile phase was maintained at $25^{\circ} \mathrm{C}$. Analyses were

213 performed under dim light to prevent sample degradation by photo-oxidation. Three

214 concentrations of lycopene standard in the range $0.01-0.03 \mathrm{mg} / \mathrm{mL}$ were injected and peak

215 area and peak height were determined. Lycopene content in the samples were identified by

216 comparing peak retention time. The contents of lycopene were expressed as milligrams per

$217100 \mathrm{~g}$ wet weight.

218 2.4.3. Antioxidant activity test

219 2.4.3.1. 2, 2-Diphenyl-l-picrylhydrazyl radical scavenging capacity assay (DPPH)

220 DPPH scavenging activity assay was performed as per the method described by Sanchez-

221 Moreno (2002) with a slight modification. For extraction, $1.25 \mathrm{~g}$ of tomato sample was

222 weighed and $25 \mathrm{ml}$ of methanol was added to it. Following this the sample was

223 homogenised in a $50 \mathrm{ml}$ tube with an Ultra-Turrax T-25 tissue homogeniser for $1 \mathrm{~min}$ at

$22424,000 \mathrm{rpm}$. The samples are then thoroughly mixed with a vortex mixer (V400 Multitude

225 Vortexer, Alpha laboratories) for $2 \mathrm{hrs}$ at $150 \mathrm{rpm}$. Then it was centrifuged for $15 \mathrm{~min}$ at

$2263,000 \mathrm{rpm}$ using a Sanyo MSE Mistral 3,000i, UK. Following centrifugation, $10 \mathrm{ml}$ samples

227 of the supernatant were filtered through PTFE syringe filters (pore size $0.45 \mu \mathrm{m}$,

228 Phenomenex, UK). Finally the extracts were stored at $-20^{\circ} \mathrm{C}$ in foil covered plastic test

229 tubes for further analysis. In a $1.5-\mathrm{mL}$ Eppendorf tube $500 \mu \mathrm{l}$ of appropriately diluted

230 methanolic extract and $500 \mu \mathrm{l}$ DPPH Reagent were added and vortexed. After that they

231 were kept for 30 min in dark. The absorbance of the supernatant was read at $515 \mathrm{~nm}$ in $1 \mathrm{ml}$

232 plastic cuvettes. Each sample of the three batches was measured in triplicate. The blank was $233 \mathrm{MeOH}$. 
235 The FRAP assay was carried out as described by Stratil, Klejdus and Kuban (2006) with a

236 slight modification. For extraction, $1.25 \mathrm{~g}$ of tomato sample was weighed and $25 \mathrm{ml}$ of

237 methanol was added to it. Following this the sample was homogenised in a $50 \mathrm{ml}$ tube with

238 an Ultra-Turrax T-25 tissue homogeniser for $1 \mathrm{~min}$ at 24,000 rpm. The samples are then

239 thoroughly mixed with a vortex mixer (V400 Multitude vortexer, Alpha laboratories) for 2

$240 \mathrm{hrs}$ at $150 \mathrm{rpm}$. Then it was centrifuged for $15 \mathrm{~min}$ at 3,000 rpm using a Sanyo MSE Mistral

$2413000 \mathrm{i}$, UK. Following centrifugation, $10 \mathrm{ml}$ samples of the supernatant were filtered

242 through PTFE syringe filters (pore size $0.45 \mu \mathrm{m}$, Phenomenex, UK). The extracts were

243 stored at $-20^{\circ} \mathrm{C}$ in foil covered plastic test tubes for further analysis.

244 The FRAP reagent was prepared by mixing $38 \mathrm{mM}$ sodium acetate (anhydrous) in distilled

245 water $\mathrm{pH} 3.6,20 \mathrm{mM} \mathrm{FeCl} 3.6 \mathrm{H}_{2} \mathrm{O}$ in distilled water and $10 \mathrm{mM}$ 2,4,6-tri(2-pyridyl)-s-

246 triazine (TPTZ) in $40 \mathrm{mM} \mathrm{HCl}$ in proportions of 10:1:1. This reagent was freshly prepared

247 before each experiment. In a $1.5 \mathrm{~mL}$ Eppendorf tube $100 \mu \mathrm{l}$ of appropriately diluted

248 methanolic extract and $900 \mu \mathrm{l}$ FRAP Reagent were added and vortex. After that they were

249 kept for $40 \mathrm{~min}$ in the heating blocks at $37^{\circ} \mathrm{C}$, covered with tin foil. The absorbance of the

250 supernatant was read at $593 \mathrm{~nm}$ in $1 \mathrm{ml}$ plastic cuvettes. Each sample of the three batches

251 was measured in triplicate. The blank was $\mathrm{MeOH}$.

252 2.4.4. Total phenols

253 For extraction, $1.25 \mathrm{~g}$ of tomato sample was weighed and $25 \mathrm{ml}$ of methanol was added.

254 Following this the sample was homogenised in a $50 \mathrm{ml}$ tube with an Ultra-Turrax T-25

255 tissue homogeniser for $1 \mathrm{~min}$ at 24,000 rpm. The samples are then thoroughly mixed with a

256 vortex mixer (V400 Multituve Vortexer, Alpha laboratories) for $2 \mathrm{hrs}$ at $150 \mathrm{rpm}$. Then it

257 was centrifuged for 15 min at 3,000 rpm using a Sanyo MSE Mistral 3000i, UK. Following 
258 centrifugation, $10 \mathrm{ml}$ samples of the supernatant were filtered through PTFE syringe filters

259 (pore size $0.45 \mu \mathrm{m}$, Phenomenex, UK). Finally the extracts were stored at $-20^{\circ} \mathrm{C}$ in foil

260 covered plastic test tubes for further analysis. Total polyphenol content of tomatoes was

261 determined using the Folin-Ciocalteu method (Singleton, Orthofer \& Lamuela-Ravento,

262 1999). In a $1.5 \mathrm{~mL}$ Eppendorf tube, $100 \mu \mathrm{l}$ of appropriately diluted methanolic extract, 100

$263 \mu \mathrm{l}$ of $\mathrm{MeOH}$ and $100 \mu \mathrm{l}$ of FC reagent were added and vortexed. After exactly $1 \mathrm{~min}, 700$

$264 \mu \mathrm{l}$ of sodium carbonate $(20 \%)$ was added, and the mixture was vortexed and allowed to

265 stand at room temperature in the dark for $20 \mathrm{~min}$. Then the tubes were centrifuged at 13,000

$266 \mathrm{rpm}$ for $3 \mathrm{~min}$. The absorbance of the supernatant was read at $735 \mathrm{~nm}$ in $1 \mathrm{ml}$ plastic

267 cuvettes. The blank was $\mathrm{MeOH}$. Each sample of the three batches was measured in

268 triplicate. Results were expressed as mg/L gallic acid equivalents (GAE).

269 2.4.5. Minerals

270 Mineral analysis was performed on $3 \mathrm{~g}$ tomatoes (Hernandez-Suarez, Rodriguez \& Romero,

271 2007). The samples were ashed at $550^{\circ} \mathrm{C}$ for $5 \mathrm{hrs}$ and transferred quantitatively into $100 \mathrm{ml}$

272 volumetric flask. Then they were digested with a few drops of $\mathrm{HCl}$ and brought to volume

273 with deionized $\mathrm{H}_{2} \mathrm{O}$. The sample solution was analysed for Sodium (Na), Potassium (K),

274 Calcium $(\mathrm{Ca})$, Magnesium $(\mathrm{Mg})$, Iron $(\mathrm{Fe})$, Copper $(\mathrm{Cu})$, Zinc $(\mathrm{Zn})$ and Manganese $(\mathrm{Mn})$

275 using an Atomic Absorption Spectrophotometer (Model IL357, USA). Calibration was

276 done according to the operator's manual. The standards were prepared from the standard

277 solutions taking into account the linear range for each element. Both samples and standards

278 contained $1 \mathrm{ml}$ of lanthanum solution/100 ml.

279 2.5. Antioxidant Activity of Whey Permeates (DPPH and FRAP) 
280 The 3 whey permeate (PC, DP and DC) solutions were prepared individually in distilled

281 water to give a final concentration of $3 \%(\mathrm{v} / \mathrm{v})$. The antioxidant activity was measured by

282 DPPH and FRAP as mentioned in 2.4.3.1. and 2.4.3.2.

\section{2.6. Statistical analysis}

284 Data were analysed by multivariate analysis of variance (MANOVA) using Statgraphics

285 software (centurium XV; Statistical Graphics Co., Rockville, USA) for different washing

286 treatments. Analysis of variance one-way (ANOVA) was used to analyse each treatment

287 over storage. In the case of significant differences LSD range test $(\mathrm{p}<0.05)$ was used.

\section{$288 \quad 3 . \quad$ Results and Discussion}

\section{3.1. Nutritional markers of Fresh-cut Tomato}

290 3.1.1. Ascorbic acid

291 The average concentration of ascorbic acid was found to be $15 \mathrm{mg} / 100 \mathrm{~g} \mathrm{FW}$ in the current

292 study, which is within the range of 6.96 to $21.23 \mathrm{mg} / 100 \mathrm{~g} \mathrm{FW}$ reported by Toor and

293 Savage (2005). No significant difference was observed between whey permeate and

294 chlorine treatments in terms of vitamin C content. However, samples treated with water

295 showed the lowest ascorbic acid content after 10 days of storage (Figure 1A). Vitamin C

296 concentration showed no substantial variations throughout the storage time in all the

297 treatments. This trend was in accordance with the values observed by other authors (Gil et

298 al., 2002; Toor \& Savage 2005). The maintenance of vitamin C concentration in fresh-cut

299 tomatoes may be explained through the low presence of $\mathrm{O}_{2}$ inside the trays (12\% at day 10).

300 Soliva-Fortuny, Oms-Oliu and Martin-Belloso (2002) reported that the magnitude of

301 vitamin $\mathrm{C}$ degradation can be related to the $\mathrm{O}_{2}$ concentrations inside the packages. The

302 higher amount of $\mathrm{O}_{2}$ in the bags headspace might cause the greater decrease in vitamin $\mathrm{C}$ 
303 content. Therefore, the initial decrease in the ascorbic acid content might be explained by

304 higher $\mathrm{O}_{2}$ concentration inside the packages initially (19\% at day 1). Consistently, Gil et al.

305 (2002) reported a non-significant decrease of vitamin $\mathrm{C}$ due to cutting in fruits such as

306 mango, strawberry and watermelon. High titratable acidity is responsible for the stability of

307 ascorbic acid in fruits. Tomato is a highly acidic fruit; it showed a relatively stable ascorbic

308 acid content during post-harvest storage. In addition, phenolic substances have been

309 reported to have a protective effect on the ascorbic acid. Therefore, the presence of

310 phenolics and flavanoids in tomato cells might have contributed to the maintenance of the

311 ascorbic acid content. It has been reported that ascorbic acid contributes by $28-38 \%$ to the

312 antioxidant activity, while the remaining activity is mainly due to phenolics (Toor \&

313 Savage, 2005).

314 3.1.2. Lycopene

315 Lycopene content of fresh-cut tomato was analysed during 10 days of storage after

316 treatments with different types of whey permeate. The average amount of lycopene in the

317 samples was $5.86 \mathrm{mg} / 100 \mathrm{~g} \mathrm{FW}$. The treatments did not show any significant effect

$318(\mathrm{p}<0.05)$ on the lycopene concentration of the samples as they followed the same pattern

319 during storage. However, storage time had significant effect $(\mathrm{p}<0.05)$ on the samples. The

320 lycopene content increased slightly at day 3, though not significantly (Figure 1B). At day 7 ,

321 lycopene concentration of the samples decreased by around $0.2 \mathrm{mg} / 100 \mathrm{~g} \mathrm{FW}$ in all the

322 treatments. This could be explained by slow degradation of lycopene during storage. The

323 samples showed a moderate increase at day 10. Fruits biosynthesise carotenoids during

324 ripening throughout storage time. On the other hand, Shi and Le Maguer (2000) observed

325 that carotenoids are susceptible to oxidation in the presence of light, oxygen and low $\mathrm{pH}$.

326 Consequently, the increase in the lycopene concentration at day 10 might be due to the 
327 biosynthesis of lycopene induced by ripening and the low oxidation of this carotenoid as a

328 result of low availability of $\mathrm{O}_{2}$ in the package headspace (Odriozola-Serrano, Soliva-

329 Fortuny \& Martin-Belloso, 2008).

330 3.1.3. Antioxidant activity test

331 3.1.3.1. 2, 2-Diphenyl-1-picrylhydrazyl radical scavenging capacity assay (DPPH)

332 The antioxidant capacity as measured by DPPH radical scavenging activity differed

333 significantly $(\mathrm{p}<0.05)$ between treatments (Figure 1C). All three whey permeates showed

334 significantly $(\mathrm{p}<0.05)$ higher DPPH reduction than chlorine and water treatment. The higher

335 antioxidant activity of whey permeates treated samples could be associated with the

336 intrinsic antioxidant activity of whey permeates $(41.60-53.82 \mathrm{mg}$ Trolox/L, as measured

337 by $\mathrm{DPPH})$. Whey permeates might have also helped to retain the antioxidant activity of

338 tomato slices. The water treated samples had the lowest DPPH reduction of all the

339 treatments. These results could be related to the total phenolic content of the samples since

340 the samples containing higher phenolic content exhibited stronger DPPH reduction and vice

341 versa.

342 On the other hand, the antioxidant capacity of fresh-cut tomatoes depleted with storage time

343 irrespective of the treatments. The antioxidant activity was reduced by around $11 \%$ from

344 day 1 to day 3 . This initial reduction could be associated with the stress caused by minimal

345 processing. Significant differences on antioxidant capacity were observed by other

346 researchers as a consequence of minimal processing. A decrease in the antioxidant capacity

347 after processing was observed in fresh-cut spinach (Gil et al., 2002). Lana and Tijskens

348 (2006) reported that fresh-cut tissues are primarily subjected to oxidative stress, causing

349 membrane damage and altering the composition and content of antioxidant compounds,

350 resulting in the reduction of the total antioxidant activity of the tissue. 


\subsubsection{Ferric ion reducing antioxidant power assay (FRAP)}

352 Ferric ion reducing antioxidant power (FRAP) is one of the most commonly used 353 antioxidant capacity assay (Kong \& Xiong, 2006). FRAP value of fresh-cut tomatoes

354 decreased significantly during storage in all treatments (Figure 1D). Similar results were 355 observed in the other antioxidant capacity assay (DPPH). The decrease of FRAP value was

356 slow until day 3. After day 3, the samples showed a sharp decrease in their antioxidant 357 capacity $($ FRAP). The treatments showed a significant difference $(\mathrm{p}<0.05)$ in terms of their

358 FRAP values during storage, DP exhibited the highest FRAP value after 10 days of storage

359 followed by DC and PC. Chlorine treated samples showed a significantly lower FRAP

360 value compared to whey permeates (DP and DC). In general whey permeates and chlorine

361 treatments showed significantly $(\mathrm{p}<0.05)$ higher antioxidant capacity measured by FRAP

362 than water treatment.

\section{3.1.4. Total phenols}

364 The average concentration of total phenols in samples at day 1 was $20.3 \mathrm{mg}$ GAE/100 g

365 FW. This value was in accordance with other studies (Toor \& Savage, 2005, Gil et al.,

366 2002). Martinez-Valverde, Periago, Provan and Chesson (2002) reported a concentration of

$36727.2 \mathrm{mg} / 100 \mathrm{~g}$ FW for phenolic compounds in tomatoes. The treatments differed

368 significantly over storage time (Figure 2). Water treatment showed the lowest phenolic

369 content of all the treatments. DP and PC maintained significantly $(\mathrm{p}<0.05)$ higher total

370 phenols than the chlorine treatment, while DC showed similar results to chlorine. The total

371 phenol content decreased significantly $(\mathrm{p}<0.05)$ during storage irrespective of treatments.

372 Phenolic content was not significantly affected by minimal processing. The decrease was

373 slow until day 3. After this all the treatments demonstrated a rapid decrease in the total

374 phenolic content. Water treated samples decreased the most to a value of around $15 \mathrm{mg}$ 
375 GAE/100 g FW after 10 days of storage. Phenolics are the major antioxidant compounds in

376 plant extracts. Toor and Savage (2005) reported that phenolic compounds might contribute

37760 to $70 \%$ antioxidant activity of tomato extracts.

\section{3.1.5. Correlation among DPPH, FRAP and Total phenol}

379 A significant correlation $(\mathrm{p}<0.05)$ between radical scavenging activities as measured using

380 the FRAP and DPPH assays was observed (Correlation Co-efficient, $\mathrm{R}^{2}=0.8005, \mathrm{p}<0.05$ ).

381 In addition, antioxidant capacities were strongly correlated with phenol content $\left(\mathrm{R}^{2}=0.9173\right.$,

$382 \mathrm{p}<0.05$ for FRAP vs Phenols and $\mathrm{R}^{2}=0.8227, \mathrm{p}<0.05$ for DPPH vs Phenols) (Table 1).

383 These results suggest that the DPPH and FRAP antioxidant activity could be predicted on

384 the basis of total phenol assay. The results emphasised the importance of phenolic

385 compounds in the antioxidant behaviour of fresh-cut tomato and indicated that the phenolic

386 compounds contributed significantly to the total antioxidant activity. Total phenol assay

387 though used for determining total phenolic content follows the same principle as electron-

388 transfer based antioxidant activity tests.

389 3.1.6. Minerals

390 Table 2 shows the results for the concentrations of the minerals and trace elements studied

391 during storage for 10 days after treatments with whey permeate and chlorine. $\mathrm{Ca}, \mathrm{Mn}$ and

$392 \mathrm{Zn}$ were the most stable elements, with no significant variation due to storage time.

393 Samples treated with PC showed the highest Zn content while the DC treated samples had

394 the lowest. Fresh-cut tomatoes did not show any significant $(\mathrm{p}<0.05)$ difference in $\mathrm{Ca}, \mathrm{Mg}$,

$395 \mathrm{Cu}, \mathrm{Fe}$ and $\mathrm{Mn}$ content after the washing treatments. However, treatments did affect the $\mathrm{Na}$,

396 K and Zn content of the samples. Samples treated with whey permeate showed significantly

$397(\mathrm{p}<0.05)$ higher values of $\mathrm{Na}$ and $\mathrm{K}$ compared with water treated samples throughout the

398 storage. The intrinsic mineral content of the whey permeates might have contributed to 
399 these higher values. $\mathrm{Na}, \mathrm{K}, \mathrm{Mg}$ and $\mathrm{Fe}$ showed a significant decreasing trend $(\mathrm{P}<0.05)$

400 during storage regardless of the treatments. Since minerals are not metabolised and

401 therefore their contents should not change, variations of mineral content of fresh-cut

402 tomatoes during storage have been attributed to redistribution of mineral elements in the

403 fruit slices (Hernández Suarez et al., 2007). Another explanation of the minerals could be

404 leaching out of tomato juice during storage.

405 3.2. Antioxidant activity test of whey permeates (DPPH and FRAP)

406 Radical quenching is a primary mechanism of antioxidants to inhibit oxidative processes.

407 DPPH is a relatively stable organic radical, thus widely used as a substrate to evaluate the 408 efficacy of antioxidants (Sanchez-Moreno, 2002). In our DPPH test, whey permeates

409 reduced the DPPH radical to a yellow-coloured compound, apparently due to the DPPH 410 radical accepting an electron or hydrogen to become a stable diamagnetic molecule. The 411 reduced DPPH radical electron spin resonance (ESR), signal intensity in the presence of the

412 whey permeate samples indicated that mixed peptides/amino acids were capable of

413 quenching DPPH presumably by pairing the odd electron of the DPPH radicals (Table 3).

414 The antioxidant potential of the whey permeates were also estimated using the FRAP assay, 415 which measures their ability to reduce a TPTZ-Fe(III) complex to a TPTZ-Fe(II) complex. 416 The reducing power (reported as FRAP values) of the whey permeates are presented in 417 Table 3 . The reducing power assay is the most effective means to evaluate the ability of 418 antioxidants to donate electrons. The strong reducing power of the whey may be due to the 419 increased availability of hydrogen ions produced by peptide hydrolysis (Kong \& Xiong, 420 2006). Colbert and Decker (1991) found that the efficacy of proteins or peptides depended 421 on their molecular weights, and peptides of lower molecular weight have strongest 
422 antioxidant activity. Whey permeate was found to contain peptides that were heat stable and

423 had a molecular weight of 500-5,000 Daltons.

424 Previous studies have shown that whey contains a broad range of antioxidant activity in an

425 iron-catalysed liposome oxidation system (Peña-Ramos \& Xiong, 2003) or a copper-

426 catalysed liposome emulsion (Colbert \& Decker, 1991), depending on the proteases used.

427 Whey hydrolysates applied to cooked meat pork patties could suppress lipid oxidation

428 (Peña-Ramos \& Xiong, 2003). Individually, both hydrolysed lactalbumin and lactoglobulin

429 could act as antioxidants (Hernández-Ledesma, Dávalos, Bartolomé, \& Amigo, 2005).

430 Coronadoa, Troutb, Dunsheac and Shaha (2002) used rosemary extract and whey powder

431 for the oxidative stability of wiener sausages during 10 months frozen storage and they

432 found improved sensory scores as compared to wieners without additional antioxidant.

433 They suggested that whey powder could have acted as a potential antioxidant.

\section{4. Conclusion}

435 The total phenol content and antioxidant activities measured by DPPH and FRAP were 436 significantly $(\mathrm{p}<0.05)$ higher in DP treated tomato samples than the industrial standard, 437 chlorine treated samples during storage. DP showed significantly better or similar results to 438 the other whey permeates (PC and DC) in all the markers tested. Water treated samples 439 retained the least antioxidants. These results suggested whey permeate could be a promising 440 alternative to maintain and also to enhance the nutritional quality of fresh-cut tomatoes. 441 However, further research is required to identify and characterise those low molecular 442 weight antioxidants. Methods to isolate these compounds commercially are also needed in 443 order to bring these antioxidants to the market.

\section{Acknowledgement}


445 The authors would like to acknowledge the financial support of the DIT Strand I Research

446 Project (2006-2010). Thanks to Glanbia (Ltd Ingredients, Ireland) for supplying the whey

447 permeate, to Amcor Flexible Ltd. for providing OPP film and to Sharp Interpack for the 448 polypropylene trays.

\section{References}

450 Artes, F., Conesa, M. A., Hernandez, S., \& Gil, M. (1999). Keeping quality of fresh-cut tomato. Postharvest Biology and Technology 17, 153-162.

452 Colbert, L. B., \& Decker, E. A. (1991). Antioxidant activity of an ultrafiltration permeate 453 from acid whey. Journal of Food Science, 56, 1249-1250.

454 Coronadoa, S. A., Troutb, G. R., Dunsheac, F. R., \& Shaha, N. P. (2002). Antioxidant effects of rosemary extract and whey powder on the oxidative stability of wiener

del Mar Contreras, M., Hernández-Ledesma, B., Amigo, L., Martín-Álvarez, P.J., Recio, I. Production of antioxidant hydrolyzates from a whey protein concentrate with thermolysin: Optimization by response surface methodology, LWT - Food Science and Technology (2010), doi:10.1016/j.lwt.2010.06.017.

Gil, M. I., Aguayo, E., \& Kader, A. A. (2002). Quality and nutrient retention in fresh-cut

Giovannucci, E. (2002). A Review of Epidemiologic Studies of Tomatoes, Lycopene, and Prostate Cancer. Experimental Biology and Medicine, 227 (10), 852-859.

466 Hernandez-Suarez, M., Rodriguez, R. E. M., \& Romero, D. C. (2007). Mineral and trace 467 element concentrations in cultivars of tomatoes. Food Chemistry, 104, 489-499. 
468 Hernández-Ledesma, B., Dávalos, A., Bartolomé, B., \& Amigo, L. (2005). Preparation of antioxidant enzymatic hydrolysates from $\alpha$-lactalbumin and $\beta$-lactoglobulin. Identification of active peptides by HPLC-MS/MS. Journal of Agricultural and Food Chemistry, 53, 588-593.

Hua, G., \& Reckhow, D. A. (2007). Comparison of disinfection by product formation from chlorine and alternative disinfectants. Water Research, 41, 1667-1678.

Kong, B. H., \& Xiong, Y. L. (2006). Antioxidant activity of zein hydrolysates in a liposome system and the possible mode of action. Journal of Agricultural and Food Chemistry, 54, 6059-6068.

Lana, M. M., \& Tijskens, L. M. M. (2006). Effect of cutting and maturity on antioxidant activity of fresh-cut tomatoes. Food Chemistry, 97, 203-211.

Lavelli, V., Peri, C., \& Rizzolo, A. (2000). Antioxidant activity of tomato products as studied by model reactions using xanthine oxidase, myeloperoxidase, and copperinduced lipid peroxidation. Journal of Agricultural and Food Chemistry, 48, $1442-1448$.

Lee H.S., \& Castle, W.S. (2001). Seasonal changes of carotenoid pigments and color in Hamlin, Eartygold, and Budd Blood orange juices. Journal of Agricultural \& Food Chemistry, 49, 877-882.

Marshall, K. (2004). Therapeutical applications of whey protein. Alternative Medicine Review, 9, 136-156.

Martin-Diana, A. B., Rico, D., Frias, J. M., Mulcahy, J., Henehan, G. T. M., \& BarryRyan, C. (2006). Whey permeate as a bio-preservative for shelf life maintenance of fresh-cut vegetables. Innovative Food Science and Emerging Technology, 7, 112-123. 
492 Martinez-Valverde, I., Periago, M. J., Provan, G., \& Chesson, A. (2002). Phenolic compounds, lycopene and antioxidant activity in commercial varieties of tomato (Lycopersicum esculentum). Journal of the Science of Food and Agriculture, 82, $323-330$.

Meléndez-Martínez, A. J., Fraser, P. D. \& Bramley, P. M. (2010). Accumulation of health promoting phytochemicals in wild relatives of tomato and their contribution to in

Mukhopadhyay, A. K. (2007). Antioxidants - Natural and Synthetic. Germany: Amani Int. vitro antioxidant activity. Phytochemistry 71, 1104-1114.

Nykänen, A., Lapvetelainen, A., Hietnen, R. M., \& Kallio, H. (1998). The effect of lactic acid, nisin whey permeate, sodium chloride and related combinations on aerobic plate count and the sensory characteristics of rainbow trout. LebensmittelWissenschaft und-Technologie, 31, 286-290.

Odriozola-Serrano, I., Soliva-Fortuny, R., \& Martin-Belloso, O. (2008). Effect of minimal processing on bioactive compounds and color attributes of fresh-cut tomatoes. Lebensmittel-Wissenschaft und-Technologie, 41, 217-226.

508 Peña-Ramos, E. A., \& Xiong, Y. L. (2003). Whey and soy protein hydrolysates inhibit lipid oxidation in cooked pork patties. Meat Science, 64, 259-263.

510 Permyakov, E. A. \& Berliner, L. J. (2000). $\alpha$-Lactalbumin: structure and function. FEBS Letter, 473, 269-274.

512 Ponce, A. G, Roura S. I, del Valle, C. E., \& Fritz, R. (2002). Characterization of native 513 microbial population of Swiss Chaed (Beta vulgaris, type cicla). LebensmittelWissenschaft und-Technologie, 37, 199-204. 
515 Sanchez-Moreno, C. (2002). Methods used to evaluate the free radical scavenging activity 516 in foods and biological systems. Food Science and Technology International, 8, $517 \quad 121-137$.

518 Sgherri, C., Kadlecova, Z., Pardossi, A., Navari-Izzo, F., \& Izzo, R. (2008). Irrigation with 519 diluted sea water improves the nutritional value of cherry tomatoes. Journal of 520 Agricultural and Food Chemistry, 56, 3391-3397.

521 Shi, J., \& Le Maguer, M. (2000). Lycopene in tomatoes: chemical and physical properties affected by food processing. Critical Reviews in Food Science and Nutrition, $40(1), 1-42$.

524 Singh, N., Singh, R. K., Bhunia, A. K., \& Stroshine, R. L. (2002). Efficacy of chlorine 525 dioxide, ozone, and thyme essential oil or a sequential washing in killing 526 Escherichia coli O157:H7 on lettuce and baby carrots. Lebensmittel-Wissenschaft $527 \quad$ und-Technologie, 35, 720-729.

528 Singleton, V. L., Orthofer, R., Lamuela-Raventos, R. R. (1999). Analysis of total phenols 529 and other oxidation substrates and oxidants by means of Folin-Ciocalteu reagent. 530 Methods in Enzymology, 299, 152-178.

531 Soliva-Fortuny, R. C., Oms-Oliu, G., \& Martin-Belloso, O. (2002). Effects of ripeness 532 stages on the storage atmosphere, colour, and textural properties of minimally processed apple slices. Journal of Food Science, 67(5), 1958-1963.

534 Stratil, P., Klejdus, B., \& Kuban, V. (2006). Determination of total content of phenolic 535 compounds and their antioxidant activity in vegetables - evaluation of 536 spectrophotometric methods. Journal of Agricultural Food Chemistry, 54, 607537 616. 
538 Toor, R. K., \& Savage, G. P. (2005). Antioxidant activities in different fractions of tomato.

$539 \quad$ Food Research International, 38, 487-494.

540 WHO (2003). Diet, nutrition and the prevention of chronic diseases. World Health

541 Organization, ISSN 0512-3054; 916. Technical Report Series (p. 149). Geneva:

$542 \quad$ World Health Organization.

543 Yalcin, A. S. (2006). Emerging Therapeutic Potential of Whey Proteins and Peptides.

$544 \quad$ Current Pharmaceutical Design, 12 (13), 1637-1643. 

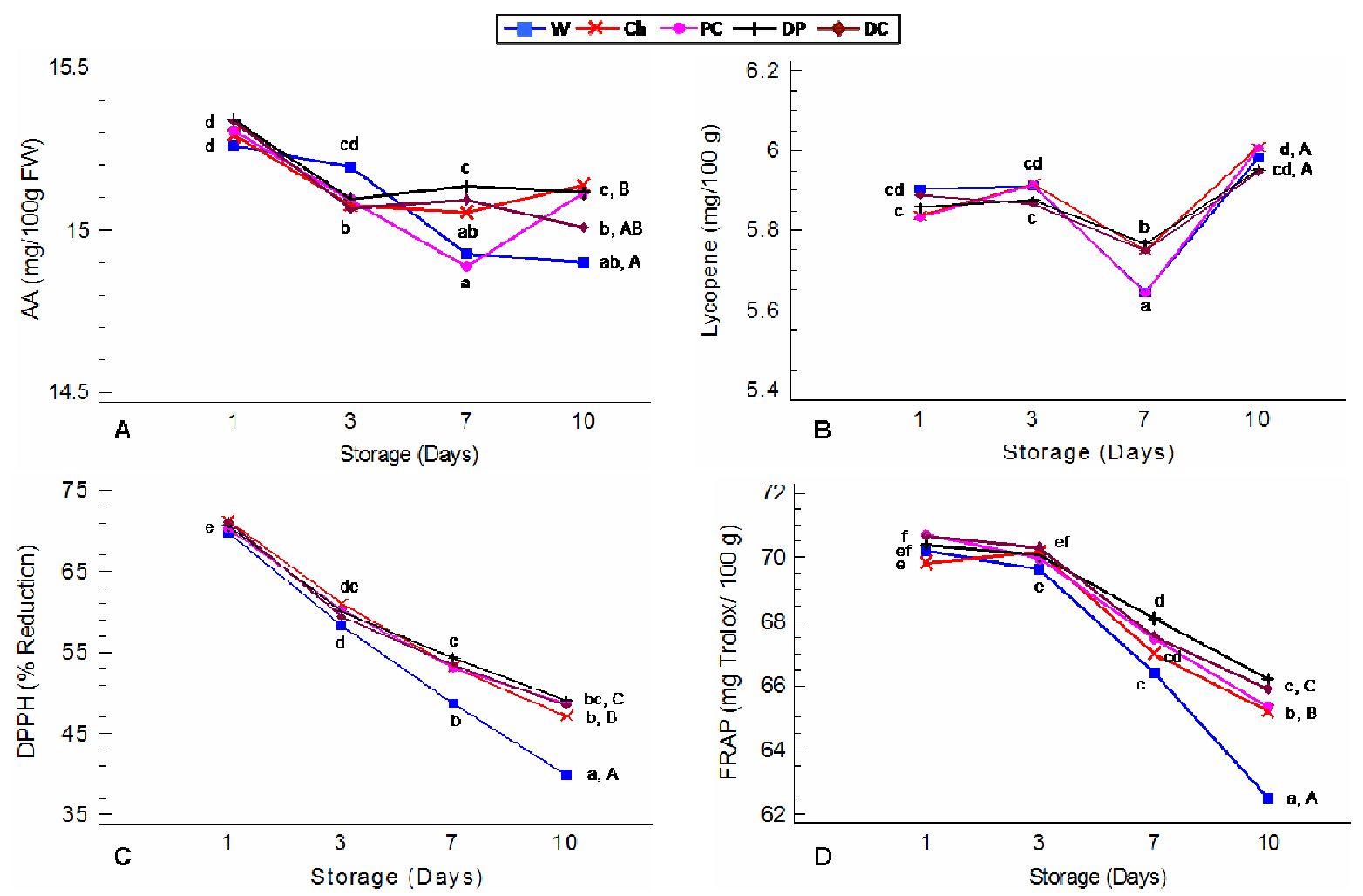

547 Figure 1. Ascorbic acid (A), lycopene (B), DPPH (C) and FRAP (D) in fresh-cut tomatoes

548 treated with chlorine (Ch), water (W) and whey permeate concentrate (PC), whey

549 delactosed permeate (DP) and whey delactosed concentrate (DC) during the 10 days of 550 storage at $4^{\circ} \mathrm{C}$. Points designated on any curve by the different letters are significantly 551 different $(\mathrm{p}<0.05)$. Lowercase letters are used for comparisons during storage and uppercase 552 letters for treatment comparisons. Three independent trials were carried out in triplicate. 


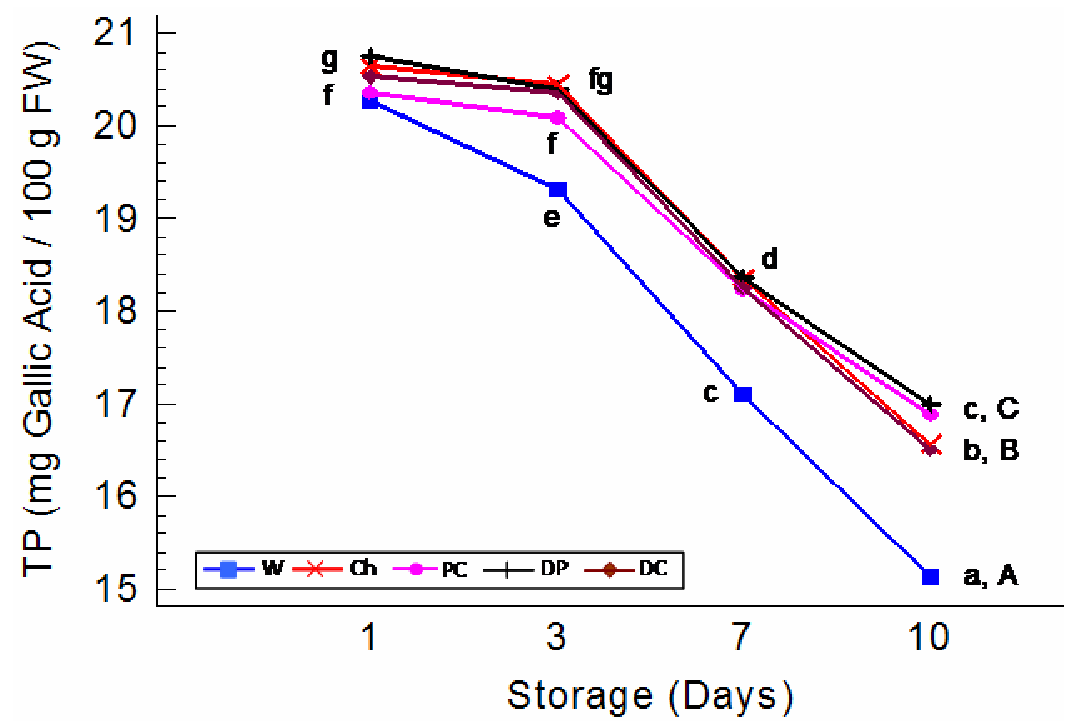

555 Figure 2. Total phenols content after treatment with chlorine $(\mathrm{Ch})$, water (W) and whey 556 permeate concentrate (PC), whey delactosed permeate (DP) and whey delactosed 557 concentrate (DC) at $4^{\circ} \mathrm{C}$ in fresh-cut tomatoes in 10 days of storage. Points designated on 558 any curve by the different letters are significantly different $(\mathrm{p}<0.05)$. Lower case letters are 559 used for comparisons during storage and upper case letters for treatment comparisons. 560 Three independent trials were carried out in triplicate. 
561 Table 1. Correlations between the results obtained from total phenolic content (TP), 2, 2-

562 Diphenyl-1-picrylhydrazyl radical scavenging capacity (DPPH) and ferric reducing

563 antioxidant power (FRAP) assays in fresh-cut tomato packages throughout the 10 days of

564 storage at $4{ }^{\circ} \mathrm{C}$ treated with water, chlorine and whey permeates.

\begin{tabular}{lll}
\hline Correlation between & Linear equations of relationship & $\begin{array}{l}\text { Correlation } \\
\text { coefficient }\left(\boldsymbol{R}^{\mathbf{2}}\right)\end{array}$ \\
\hline FRAP and DPPH & $Y(\mathrm{FRAP})=0.2294 X(\mathrm{DPPH})+54.971$ & 0.8005 \\
FRAP and TP & $Y(\mathrm{FRAP})=1.2672 X(\mathrm{TP})+44.194$ & 0.9173 \\
DPPH and TP & $Y(\mathrm{DPPH})=4.6816 X(\mathrm{TP})-31.05$ & 0.8227 \\
\hline
\end{tabular}


566 Table 2. Changes in mineral content (mg/100 $\mathrm{g} \mathrm{FW})$ in fresh-cut tomato during storage at $56744^{\circ} \mathrm{C}$ treated with $120 \mathrm{ppm}$ chlorine $(\mathrm{Ch})$, water $(\mathrm{W})$ and whey permeate concentrate $(\mathrm{PC})$, 568 whey delactosed permeate (DP) and whey delactosed concentrate (DC). ${ }^{1}$

\begin{tabular}{|c|c|c|c|c|c|c|}
\hline \multirow[t]{2}{*}{ Mineral } & \multirow[t]{2}{*}{ Treatment } & \multirow{2}{*}{$\begin{array}{l}\text { Differences } \\
\text { among } \\
\text { treatments }\end{array}$} & \multicolumn{4}{|c|}{ Storage (Days) } \\
\hline & & & 1 & 3 & 7 & 10 \\
\hline \multirow[t]{5}{*}{$\mathrm{Na}$} & $\mathrm{W}$ & A & $11.32^{\mathrm{f}}$ & $9.26^{\mathrm{d}}$ & $8.06^{\mathrm{ab}}$ & $7.70^{\mathrm{a}}$ \\
\hline & $\mathrm{Ch}$ & $\mathrm{AB}$ & $10.70^{\mathrm{e}}$ & $9.44^{\mathrm{d}}$ & $8.50^{b c}$ & $7.99^{\mathrm{ab}}$ \\
\hline & $\mathrm{PC}$ & B & $11.19^{\mathrm{f}}$ & $9.17^{\mathrm{d}}$ & $8.66^{\mathrm{c}}$ & $8.25^{\mathrm{bc}}$ \\
\hline & $\mathrm{DP}$ & $\mathrm{B}$ & $11.04^{\mathrm{ef}}$ & $9.26^{\mathrm{d}}$ & $8.78^{\mathrm{cd}}$ & $8.17^{\mathrm{b}}$ \\
\hline & $\mathrm{DC}$ & B & $11.18^{\mathrm{f}}$ & $9.37^{\mathrm{d}}$ & $8.51^{b c}$ & $8.24^{b c}$ \\
\hline \multirow[t]{5}{*}{$\mathrm{K}$} & $\mathrm{W}$ & A & $246^{\mathrm{ef}}$ & $187^{\mathrm{d}}$ & $153^{c}$ & $932^{\mathrm{a}}$ \\
\hline & $\mathrm{Ch}$ & $\mathrm{AB}$ & $253^{\mathrm{f}}$ & $193^{\mathrm{de}}$ & $173^{\mathrm{cd}}$ & $113^{\mathrm{ab}}$ \\
\hline & $\mathrm{PC}$ & B & $253^{\mathrm{f}}$ & $219^{\mathrm{e}}$ & $186^{\mathrm{d}}$ & $133^{b c}$ \\
\hline & DP & B & $253^{\mathrm{f}}$ & $227^{\mathrm{ef}}$ & $160^{\mathrm{cd}}$ & $126^{\mathrm{b}}$ \\
\hline & $\mathrm{DC}$ & B & $226^{\mathrm{ef}}$ & $219^{\mathrm{e}}$ & $166^{\mathrm{cd}}$ & $140^{\mathrm{bc}}$ \\
\hline \multirow[t]{5}{*}{$\mathrm{Mg}$} & $\mathrm{W}$ & A & $126^{\mathrm{d}}$ & $121^{\mathrm{b}}$ & $121^{\mathrm{b}}$ & $118^{\mathrm{a}}$ \\
\hline & $\mathrm{Ch}$ & A & $126^{\mathrm{d}}$ & $120^{\mathrm{ab}}$ & $121^{\mathrm{b}}$ & $119^{\mathrm{ab}}$ \\
\hline & $\mathrm{PC}$ & A & $126^{\mathrm{d}}$ & $120^{\mathrm{ab}}$ & $121^{\mathrm{b}}$ & $120^{\mathrm{ab}}$ \\
\hline & DP & A & $126^{\mathrm{d}}$ & $122^{\mathrm{c}}$ & $119^{\mathrm{ab}}$ & $121^{\mathrm{b}}$ \\
\hline & $\mathrm{DC}$ & A & $127^{\mathrm{d}}$ & $121^{\mathrm{b}}$ & $118^{\mathrm{a}}$ & $120^{\mathrm{ab}}$ \\
\hline \multirow[t]{5}{*}{$\mathrm{Fe}$} & $\mathrm{W}$ & A & $2.16^{\mathrm{d}}$ & $2.03^{\mathrm{c}}$ & $1.94^{\mathrm{b}}$ & $1.88^{\mathrm{a}}$ \\
\hline & $\mathrm{Ch}$ & A & $2.16^{\mathrm{d}}$ & $2.03^{\mathrm{c}}$ & $1.95^{\mathrm{b}}$ & $1.90^{\mathrm{a}}$ \\
\hline & $\mathrm{PC}$ & A & $2.16^{\mathrm{d}}$ & $2.04^{c}$ & $1.94^{\mathrm{b}}$ & $1.90^{\mathrm{a}}$ \\
\hline & $\mathrm{DP}$ & A & $2.17^{\mathrm{d}}$ & $2.05^{\mathrm{c}}$ & $1.94^{\mathrm{b}}$ & $1.88^{\mathrm{a}}$ \\
\hline & $\mathrm{DC}$ & A & $2.16^{\mathrm{d}}$ & $2.04^{\mathrm{c}}$ & $1.94^{\mathrm{b}}$ & $1.90^{\mathrm{a}}$ \\
\hline \multirow[t]{5}{*}{$\mathrm{Zn}$} & $\mathrm{W}$ & $\mathrm{AB}$ & $0.74^{\mathrm{a}}$ & $0.73^{\mathrm{a}}$ & $0.75^{\mathrm{a}}$ & $0.73^{\mathrm{a}}$ \\
\hline & $\mathrm{Ch}$ & $\mathrm{AB}$ & $0.74^{\mathrm{a}}$ & $0.74^{\mathrm{a}}$ & $0.74^{\mathrm{a}}$ & $0.76^{\mathrm{a}}$ \\
\hline & $\mathrm{PC}$ & B & $0.74^{\mathrm{a}}$ & $0.76^{\mathrm{a}}$ & $0.76^{\mathrm{a}}$ & $0.75^{\mathrm{a}}$ \\
\hline & $\mathrm{DP}$ & $\mathrm{AB}$ & $0.74^{\mathrm{a}}$ & $0.75^{\mathrm{a}}$ & $0.76^{\mathrm{a}}$ & $0.74^{\mathrm{a}}$ \\
\hline & $\mathrm{DC}$ & A & $0.73^{\mathrm{a}}$ & $0.74^{\mathrm{a}}$ & $0.73^{\mathrm{a}}$ & $0.73^{\mathrm{a}}$ \\
\hline
\end{tabular}

$569{ }^{1}$ Values designated by the different letters are significantly different $(\mathrm{p}<0.05)$. Lowercase 570 letters are used for comparisons during storage and uppercase letters for treatment 571 comparisons. Three independent trials were carried out in triplicate. 
572 Table 3. Antioxidant Activity (DPPH and FRAP) of whey permeate concentrate (PC),

573 whey delactosed permeate (DP) and whey delactosed concentrate (DC). ${ }^{1}$

\begin{tabular}{llll}
\hline $\begin{array}{l}\text { Whey Permeates } \\
(\mathbf{3 \%})\end{array}$ & $\begin{array}{l}\text { Significance of } \\
\text { difference }\end{array}$ & $\begin{array}{l}\text { DPPH } \\
\text { mg Trolox/ } \mathbf{L}\end{array}$ & $\begin{array}{l}\text { FRAP } \\
\text { mg Trolox/ } \mathbf{~}\end{array}$ \\
\hline PC & S & $41.60 \pm 1.38$ & $135.68 \pm 1.6$ \\
DP & NS & $62.29 \pm 1.55$ & $179.86 \pm 1.2$ \\
DC & NS & $53.82 \pm 2.55$ & $178.46 \pm 0.6$
\end{tabular}

$574{ }^{\mathrm{T}} \mathrm{S}$ and NS for each sample denote significant $(\mathrm{p}<0.05)$ and non-significant $(\mathrm{p}>0.05)$ 575 difference respectively. 